\section{Commentary: Thoracoscopic ablation for the faint of heart}

\author{
Donald D. Glower, MD
}

Kim and colleagues ${ }^{1}$ present a series of 31 patients with reduced ejection fraction and persistent atrial fibrillation (AF) undergoing bilateral total thoracoscopic atrial ablation (TTA) (Figure 1). The authors concluded that TTA is a safe and effective procedure that improves left ventricular function and restores sinus rhythm in patients with AF and left ventricular dysfunction.

This is neither the first report of TTA, ${ }^{2}$ nor is it the first report of surgical AF ablation in patients with reduced ejection fraction. ${ }^{3}$ However, this may be one of the first series of TTA in patients with reduced ejection fraction. While the series is small, the follow-up is good. The illustrative video is helpful. These data reinforce the few studies of TTA and the few studies of surgical ablation in reduced ejection fraction.

This study does have limitations. First, this is a retrospective clinical series with echocardiography and rhythm assessment at irregularly timed intervals. Also of note, 8 of 31 patients did receive additional catheter ablation after the initial TTA procedure. Results are presented for all 31 patients after the last performed procedure, emphasizing the value of combined transcatheter and thoracoscopic approaches in some patients.

Thoracoscopy is not likely to replace catheter ablation, given the additional morbidity of surgical TTA over a transcatheter procedure. However, these data and others suggest that TTA may be a reasonable alternative to transcatheter ablation in patients who are low risk or who have failed transcatheter ablation or who may have other risk factors for transcatheter ablation failure, such as persistent AF.

From the Duke University Medical Center, Durham, NC

Disclosures: The author reported no conflicts of interest.

The Journal policy requires editors and reviewers to disclose conflicts of interest and to decline handling or reviewing manuscripts for which they may have a conflict of interest. The editors and reviewers of this article have no conflicts of interest.

Received for publication April 19, 2021; revisions received April 19, 2021; accepted

for publication April 22, 2021; available ahead of print April 27, 2021.

Address for reprints: Donald D. Glower, MD, Box 3851 DUMC, Durham, NC 27710

(E-mail: Glowe001@mc.duke.edu).

JTCVS Techniques 2021;8:67-8

2666-2507

Copyright (C) 2021 The Author(s). Published by Elsevier Inc. on behalf of The American Association for Thoracic Surgery. This is an open access article under the CC BY license (http://creativecommons.org/licenses/by/4.0/).

https://doi.org/10.1016/j.xjtc.2021.04.027

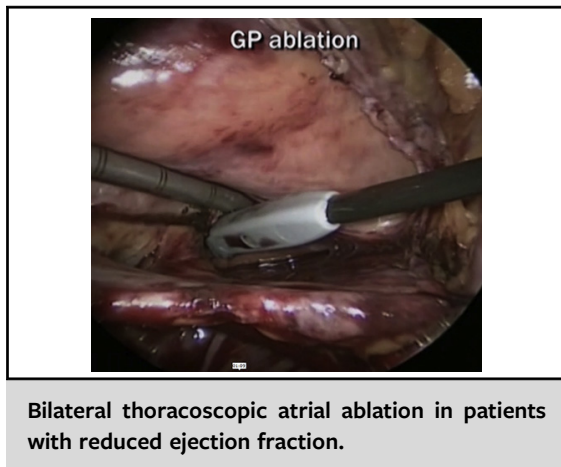

CENTRAL MESSAGE

Bilateral thoracoscopic atrial ablation in patients with reduced ejection fraction can improve ventricular function and restore sinus rhythm.

Thoracoscopic and other epicardial approaches do have advantages of access to some of the epicardial ganglion plexuses, which may be important in certain patients. Epicardial approaches can also provide access to externally occlude the left atrial appendage. ${ }^{4}$ In short, combined thoracoscopic and transcatheter approaches may be complementary. Other less-invasive surgical approaches such as the transpericardial convergent procedure ${ }^{5}$ may share with TTA the

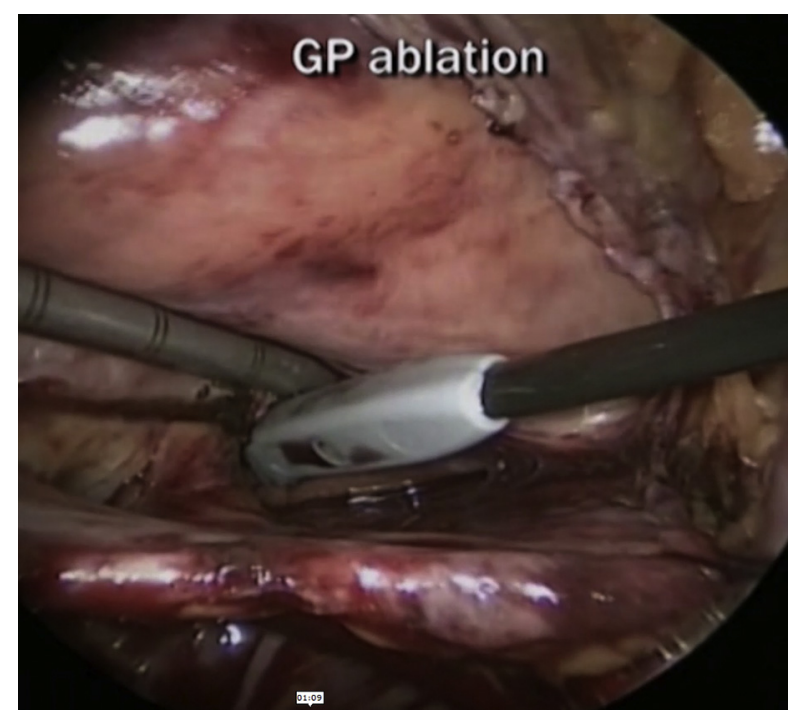

FIGURE 1. Bilateral thoracoscopic atrial ablation in patients with reduced ejection fraction. 
advantages and disadvantages of an epicardial approach over transcatheter endocardial procedures.

Thus, Kim and colleagues show that TTA can be safe and effective in patients with reduced ejection fraction. Thoracoscopic ablation may have a role, even for the faint of heart.

\section{References}

1. Kim HR, Jeong D-S, Kwon H-J, Park S-J, Park K-M, Kim JS, et al. Total thoracoscopic ablation in patients with atrial fibrillation and left ventricular dysfunction. J Thorac Cardiovasc Surg Tech. 2021;8:60-6.
2. van Laar C, Kelder J, van Putte BP. The totally thoracoscopic maze procedure for the treatment of atrial fibrillation. Interact Cardiovasc Thorac Surg. 2017;24: 102-11.

3. Stulak JM, Dearani JA, Daly RC, Zehr KJ, Sundt TM III, Schaff HV. Left ventricular dysfunction in atrial fibrillation: restoration of sinus rhythm by the Cox-maze procedure significantly improves systolic function and functional status. Ann Thorac Surg. 2006;82:494-500.

4. Franciulli M, De Martino G, Librera M, Desoky A, Mariniello A, Iavazzo A, et al. Stand-alone thoracoscopic left atrial appendage closure in nonvalvular atrial fibrillation patients at high bleeding risk. Innovations (Phila). 2020;15:541-6.

5. DeLurgio DB, Crossen KJ, Gill J, Blauth C, Oza SR, Magnano AR, et al. Hybrid convergent procedure for the treatment of persistent and long-standing persistent atrial fibrillation: results of CONVERGE clinical trial. Circ Arrhythm Electrophysiol. 2020;13:e009288. 